\title{
Assessing the Satisfaction Level of Tourists with Their Overall Experiences of Tours in the World Heritage Sites of Amhara National Regional State
}

\author{
Sisay Haile $(\mathrm{PhD})$ \\ Assistant Professor of Applied Developmental Psychology, Department of Psychology, College of Social \\ Science and Humanities, University of Gondar, P.O.Box 196, Gondar, Ethiopia
}

Derb Abiew $(\mathrm{PhD})$

Assistant Professor of Applied Linguistics and Communication, Department of English Language and Literature, College of Social Sciences and Humanities, University of Gondar, P.O.Box 196, Gondar, Ethiopia

Tewodros Abuhay(MA)

Assistant Professor of Development Studies, Department of Civics and Ethical Studies, College of Social Sciences and Humanities, University of Gondar, P.O.Box 196, Gondar, Ethiopia

\begin{abstract}
Tourist satisfaction is an important indicator to successful destination marketing because it influences tourists' choice of destination, consumption of products and services, and the their decision to stay and to return. The current study investigated tourists' perceptions towards tourism services and products provided at tourist attraction sites in Amhara Region, and determined the extent to which destinations related factors are associated with tourists' level of satisfaction. The study was conducted in four tourist attraction sites in the Amhara Region, namely, Gondar, Debark, Bahir Dar, and Lalibela. The study employed a cross-sectional research design. The sample population for this study composed of international tourists who visited tourist attraction sites in Amhara Region. Quantitative and qualitative data were collected in this study. The data were assessed with eight destination related factors (accommodation, accessibility, attractiveness, communication, environmental, infrastructural, cost, and others). The results of descriptive statistics revealed that the respondents rated most of the tourist destination attributes highly, indicating that tourists generally agreed that destination attributes in the study areas were found at satisfactory levels. The results of multiple regression analysis indicated that destination attributes such as attractiveness, communication, and cost had a positive relationship with tourist satisfaction while infrastructural, accessibility, and others had a negative relationship with tourist satisfaction. Based on the results of this study, it is recommended that destination managers and marketers should make much more efforts toward tourist satisfaction. Policy makers and managers in the tourism industry should also consider infrastructural, accessibility, and other related factors which can have a negative relationship with tourist satisfaction.
\end{abstract}

Keywords:Tourist satisfaction, destination attributes, accommodation, accessibility, attractiveness, communication, environmental, infrastructural, cost

DOI: $10.7176 /$ JTHS/43-03

Publication date:September $30^{\text {th }} 2019$

\section{Introduction}

Ethiopia has been one of the tourist destinations in the world. Indeed, as Ethiopia has been endowed with a number of cultural, historical, and natural heritages, the number of tourists coming to Ethiopia to date is increasing. In fact, tourism, being one of the economic sectors, has to play a crucial role in bringing about sustainable development to our country. As has been case, the Amhara National Regional State is the most prominent tourist destination in Ethiopia, having 4 major tourist destinations or world heritage sites namely, Fasil Castle (Gondar), Simien Mountains National Park (Debark), Lalibela Rock-hewn Churches (Lalibela) and the Monasteries of Lake Tana (Bahir Dar).

The tourism sector is therefore expected to play a crucial role in terms of bringing about significant economic benefit to the region and to the country as a whole. In this regard, Emmanuel deKadt (1979:339) as cited in Heran Tsedeke (2013:1) deduces that if undertaken consciously and methodically, tourism can make a substantial contribution to the economic and social development of many countries. According to the World Bank report (2004) one reason for continued poverty in Ethiopia is over-dependence on the agricultural sector (Ayele, 2007). But then, tourism is an option to significantly improve the livelihoods of both rural and urban communities, and it is one of the economies for unlocking the potential to provide meaningful benefits (World Bank, 2004).

Hohnholz (1994), tourism is described as being an activity, as comprising interrelated systems, including 
all temporary travel for whatever purpose, which results in one or more nights being spent away from places of work and home. Of course, as pointed out by Simmons (1994), it has been defined in many ways according to the users' own perceptions and interests. Accordingly, for economists, tourism is viewed as a route to macroeconomic growth and, particularly, a means of generating foreign exchange. For the private sector, tourism is a commercial activity and hence the main concerns are product development, competitiveness, and commercial returns. For conservationists, tourism is seen as a form sustainable use of wild resources and hence as an incentive and a way to enhance conservation.

Similarly, the definition of a 'tourist' varies from one profession to the other. Thus, scholars define the term from the perspectives of the time that the tourist spends on a particular place, from the perspective of distance traveled, the purpose, or a mixed. According to Mclntosh (1995) as cited in Teklehaymanot Hailu (2005), the definition of a tourist used by the National Tourism resource review commission (USA) in 1973 was: "A tourist is one who travels away from for a distance of at least 50 miles (one way) for business, pleasure, personal affairs, or any other purpose except to commute to work, where he/she stay overnight or returns the same day."

Rifai (2013), Secretary-General, World Tourism Organization (UNWTO) noted that with over one billion tourists travelling the world every year, tourism has become a worldwide social and cultural phenomenon that engages people of all nations as both hosts and guests. This frequent travel of people from one part of the world to the other creates a suitable opportunity for people to exchange their knowledge, cultures, values, beliefs, etc. (Louis, 1988).

\section{Statement of the Problem}

The socio-economic benefits of tourism to the local communities are highly dependent on the length of stay of the tourists at the destinations. However, studies show that the length of stay of the tourists at the four major tourist destinations in Amhara region is so short. Thus, according to the report released by the Amhara Region Culture and Tourism Bureau (2011/12, 2014 E.C.), the average number of days spent by foreign/international tourists is 3 days, 1.5 days, 3 days and 5 days for the Monasteries of Lake Tana (Bahir Dar), Fasil Castles (Gondar), Lalibela Rock-hewn Churches (Lalibela) and Simien Mountains National Park (Debark) respectively. Similarly, the average stay for domestic/local tourists is 3 days, 1.5 days, 3 days, and 5 days for the aforementioned destinations in their respective order. Such a situation, that is, short duration of tourists' stay, therefore tends to imply that there is a gap in the quality of service delivered by the concerned stakeholders seemingly at the different levels. Therefore, this in turn is very likely to have an influence on the satisfaction level tourists, the socio-economic benefit of the sector to the local community, the amount of revenue to be generated from the sector, and hence on the sustainable development of the tourism industry.

Tourism entails intercultural communication. Of course, intercultural communication, which is commonly defined as the interaction between two or more people from different cultural backgrounds, is an integral part of tourism. Needless to say, tourists are the major customers in the tourism industry and hence they are likely to be in the top priority. Globalization trends and expansion in world travel point to a future that will witness an increased interaction of persons from diverse cultures. An understanding of and sensitivity to the cultural differences and needs of others will therefore become more important for present and future hospitality management operations (Saee, 2006:83). Opportunities for cross-cultural contact have increased, and such contacts have been accompanied by misunderstanding and conflict (Kajiura, 2007:37). On the other hand, effective intercultural communication is a prerequisite to maintain the satisfaction of tourists and to generate the expected amount of economic benefit from the tourism industry.

Sometimes, as the case may be, disagreements are bound to occur between tourists and tour guides due to intercultural misunderstandings, which in turn would result in negative/ disruptive feelings. Again, this would have repercussions on the satisfaction of tourists/flow of tourists and the amount of income to be generated from the tourism sector. If the worst comes, it may also lead to conflict that could in turn damage the good image of the country and hence a negative influence on the tourism industry.

The issue of standard codes of ethics is also an important aspect of intercultural communication, which has a bearing in the effectiveness of the interaction between tourists and tour guides and other service providers. Of course, hospitality is one of the core elements in the tourism industry. Thus, all the relevant stakeholders are expected to be hospitable and hence to be so friendly, welcoming and kind while they interact with tourists. Indeed, these are cultural values or good manners we Ethiopians are to be proud of. The lack of these qualities on the part of our service providers is therefore likely to have a negative effect on the level of tourists' satisfaction.

Of course, tourism is a very delicate industry (Bizimana, 2003) which requires hospitality, peace, and tranquility in order to exist and flourish. Tourism is only possible in areas where peace is present; it is absent in war zones, and much diminished in areas of high conflict and tension (Pizam, 2002). Tourists avoid visiting places with a negative image and "easily switch to another destination" when they find there is no peace in their 
destination. For example, the development of tourism industry in Nigeria is highly jeopardized by the ongoing internal instabilities. The genocide in Rwanda, World Trade Center terrorist attack of September 11, 2000, terrorist attack of Madrid and Barcelona has diminished the number of tourists in these places (Neumayer, 2004). Peace and tourism are interrelated. Without peace there can be no tourism, but tourism can also contribute to the peace process-the building of peace (Wintersteiner and Wohlmuther, 2013).

Although the number of tourists (domestic and foreign) is increasing from time to time, arguably, the revenue generated from the sector remains to be insignificant. According to the preliminary information we got from North Gondar Woreda Culture and Tourism Office, the average length of tourist stay in Gondar City is 1.3 days, which is less than 2 days. Apparently, one of the reasons as to why tourists spend short time could therefore be their lack of intercultural communication satisfaction, which could be attributed to a number of factors at the different levels.

As a result of the findings of this paper, the quality of service to tourists will be much more improved so that huge number of tourists will come to Ethiopia than ever before. It is when tourists are satisfied with the services they are offered, we also benefit in so many ways. Besides, in spite of the fact that Ethiopia has a number of tourist attraction sites, it can be argued that the country has not yet got maximal benefit from the tourism sector. Nor does it efficiently utilize the tourism sector. This paper therefore tries to assess the level of tourists' satisfaction (using three A's: Access, Accommodation and Attraction) in their tour experience in the world heritage sites of Amhara National Regional State.

\section{Objectives of the Study}

The major aim of this project was to assess the satisfaction level of tourists with their overall experiences of the tourist sites in the world heritage sites of Amhara National Regional State.

\section{Specific Objectives}

Specifically, this paper intends to achieve the following specific objectives.

- To assess the level of satisfaction of tourists with overall services.

- To identify the differences in the level of satisfaction of tourists on the basis of their demographic backgrounds.

\section{Methods}

Tourist satisfaction is important to successful destination marketing because it influences the choice of destination, the consumption of products and services, and the decision to return (Kozak \& Rimmington, 2000). Thus, there is a need to investigate the relationship between destination attributes and tourists' satisfaction from the tourist's perspective in order to gain an in-depth understanding of tourists' attitudes and behavior after they visit destinations.

Several researchers have studied customer satisfaction and provided theories about tourism (Bowen, 2001). The current study research framework was constructed based on the extensive literature review (Middleton \& Clarke, 2001). In the review of the tourism literature, the selected attributes were crucial ones affecting tourists' satisfaction.

The current study investigated tourists' perceptions towards quality tourism services provided at tourist attraction sites in Amhara Region, and determined tourist satisfaction by examining the impact of quality tourism product on overall tourist satisfaction. More specifically, this research examined tourist satisfaction with destination attributes and identified the relationships between the destination attributes and overall tourist satisfaction.l

\section{Study Area}

The study was conducted in in Amhara Region. The study area covered four tourist attraction sites namely Gondar, Debark, Bahir Dar and Lalibela.

\section{Study Design}

The study employed across-sectional research design. The design allows data collection to be done at a single point in time and is most appropriate for sample descriptive interpretations as well as determination of relationships between and among variables.

\section{Population and Sample}

The sample population for this study composed of international tourists who visited tourist attraction sites in Amhara Region. In the context of this study, the sampling type used was convenience sampling. The convenience sampling technique was chosen because it is the most appropriate method for obtaining the exact source of the sample ordinance population willing to provide the desired information in the study. In total, 250 questionnaires were distributed and $152(60.8 \%)$ usable questionnaires were obtained. The total number of the participants was about 226.

\section{Measures}

In this study, the data were collected using the on-site survey method. Quantitative and qualitative data were 
collected in this study. The questionnaire used in this study consisted of three sections. The first section consisted of the demographics of the respondents including age, gender, marital status, total household incomes, and educational level. The second section included travel behavior characteristics and destination attributes such as means of arrival to tourist destination, hearing about tourist site, visit time of the tourist site, stay in the tourist site, reason for visit, and composition.

The third section included questions related to the research topic, including tourists' perceptions about destination attributes and satisfaction levels in relation to tourist attraction sites in Amhara Region. Indicators of destination attributes included, accommodation ( 8 items), accessibility of the destination ( 9 items), destination attractiveness (18 items), communication (13 items), environmental ( 8 items), infrastructural (4 items), cost/price (12 items), and others ( 2 items). Satisfaction was assessed using 23 items.

Respondents were requested to give a score to each of the attributes and on the levels of satisfactions using a 5-point Likert-type scale ranging from very low to very high satisfaction (where $1=$ strongly disagree, $2=$ disagree, 3 = neutral, 4 = agree, 5 = strongly agree).

The reliability of the questionnaire was calculated using the Alpha coefficient for each of eight factors in this study. Cronbach ${ }^{\text {ee }}$ Alpha coefficient was $\alpha=.91$ for accommodation, $\alpha=.89$ for accessibility, $\alpha=.74$ for attractiveness, $\alpha=.81$ for communication, $\alpha=.79$ for environmental, $\alpha=.83$ for infrastructural, $\alpha=.79$ for cost/price, and $\alpha=.84$ for satisfaction The scales in the instrument had an acceptable internal consistency because Cronbach's Alpha scores were above the recommended 0.7 level (De Vellis, 1991).

\section{Data Collection Procedures}

The initial questionnaire designed for this study was presented to a group of judges who had experience in the field. A panel of three subject matter experts reviewed the statements for face and content validity. The suggested modifications were then added to the research tool. The procedure of data collection started by receiving permission letter from the University of Gondar. This was followed by pilot study which was conducted on 30 tourists visiting Gondar.

Actual fieldwork was done over a 2-week period between January and April 2016, whereby qualitative and quantitative data collection techniques and procedures were employed. The questionnaires were distributed in the area that tourists are more likely to visit such as hotels, visitor information centers, and the airport departure lounges. Surveys were administered by the research assistants and the researchers. With the distribution of questionnaires, a letter explaining the study had been submitted. All the respondents were assured that the questionnaires would remain anonymous. The survey took roughly 30 minutes to complete and it was then pretested with random respondents.

Descriptive and inferential statistical analyses were employed to provide deeper insight into the research questions. This part of the research result is presented under three major sections. The first section provides the demographic characteristics and travel behavior characteristics of the respondents. The second section presents results on descriptive statistics of the indicators of destination attributes and satisfaction levels used in the study. The last section presents the results of multiple regressions that examined the extent to which the eight destinations related factors are associated with tourists' levels of satisfaction.

\section{5 . Results and Discussion}

\subsection{Tourist Satisfaction}

\subsubsection{Demographic and travel characteristics of the respondents}

In this section, preliminary analyses that included descriptive data about the samples are presented. Frequency and percentage analyses are computed to derive a summary of the demographic data. The demographic characteristics and travel behavior characteristics of the respondents are shown in Table 1 and Table 2. 
Table 1: Demographic characteristic of the respondents $(N=152)$

\begin{tabular}{lcc}
\hline & $f$ & $\%$ \\
\hline Age & & \\
Under 20 & 11 & 7.2 \\
$20-29$ & 34 & 22.4 \\
$30-39$ & 33 & 21.7 \\
$40-49$ & 9 & 5.9 \\
$50-59$ & 44 & 28.9 \\
Above 59 & 21 & 13.8 \\
Sex & & \\
Male & 53 & 34.9 \\
Female & 99 & 65.1 \\
Marital status & & \\
Single & 69 & 45.4 \\
Married & 83 & 54.6 \\
Education level & & \\
High school & 31 & 20.4 \\
College diploma & 10 & 6.6 \\
1 $^{\text {st degree }}$ & 22 & 14.5 \\
$2^{\text {nd degree }}$ & 68 & 44.7 \\
PhD & 21 & 13.8
\end{tabular}

The gender distribution of the respondents showed that the majority of respondents $(65.1)$ were female and 34.9 were male. The dominant age group of the respondents was 50 to 59 years $(28.9 \%)$, followed by $20-29$ years $(22.4 \%), 30$ to 39 years $(21.7 \%)$. The lowest group was 40 to 49 representing $5.9 \%$ of the respondents. With regard to respondents' marital status most of the respondents $(54.6 \%)$ reported that they are married, and $45.4 \%$ of the respondents were single. In terms of level of education, the majority of respondents $(44.7 \%)$ had $2^{\text {nd }}$ degree; $20.4 \%$ of the respondents had a secondary school education, and $13.8 \%$ of the respondents had a $\mathrm{PhD}$ degree. No respondent in the research study was at below a secondary school education.

\subsubsection{Travel behavior characteristics of the respondents}

The travel behavior characteristics of the respondents are shown in Table 2. 
Table 2: Travel behavior characteristics of the respondents $(\mathrm{N}=152)$

\begin{tabular}{|c|c|c|}
\hline & $f$ & $\%$ \\
\hline \multicolumn{3}{|c|}{ Means of Arrival to tourist destination } \\
\hline 4 wheel & 19 & 12.5 \\
\hline Bus & 11 & 7.2 \\
\hline Air & 122 & 80.3 \\
\hline \multicolumn{3}{|c|}{ Hearing about tourist site } \\
\hline Already know & 31 & 20.4 \\
\hline Friend & 64 & 42.1 \\
\hline Media & 21 & 13.8 \\
\hline Book guides & 20 & 13.2 \\
\hline others & 16 & 10.5 \\
\hline \multicolumn{3}{|c|}{ Visit time of the tourist site } \\
\hline Never & 115 & 75.7 \\
\hline Once & 9 & 5.9 \\
\hline Twice & 28 & 18.4 \\
\hline \multicolumn{3}{|c|}{ Stay in the tourist site } \\
\hline 1 day & 16 & 10.5 \\
\hline 2 days & 41 & 27.0 \\
\hline 3 days & 34 & 22.4 \\
\hline 4 days & 48 & 31.6 \\
\hline 5 days & 13 & 8.6 \\
\hline \multicolumn{3}{|l|}{ Reason for visit } \\
\hline Relax & 28 & 18.4 \\
\hline Visit relative & 13 & 8.6 \\
\hline Education & 31 & 20.4 \\
\hline Culture & 80 & 52.6 \\
\hline \multicolumn{3}{|l|}{ Composition } \\
\hline Alone & 9 & 5.9 \\
\hline With friend spouse & 67 & 44.1 \\
\hline Organized group & 67 & 44.1 \\
\hline Others & 9 & 5.9 \\
\hline
\end{tabular}

With regard to the means of arrival to tourist destination, the largest group of respondents $(80.3 \%)$ arrived by air. $12.55 \%$ of the respondents arrived by 4 wheel and the smallest group of respondents $(7.2 \%)$ by bus. The largest group of respondents $(42.13 \%)$ heard about tourist attraction sites from friends.

Past experience of respondents was measured by asking respondents to indicate their number of visits to tourist destinations. The majority of respondents, $75.7 \%$ did not have previous experience with area. Almost $18.4 \%$ of the respondents visited 1 to 2 times. Furthermore, $5.9 \%$ of the respondents visited 1 time, whereas $14.7 \%$ of the respondents visited 5 times or more.

With regard to length of stay in the tourist destination, $31.6 \%$ of the respondents stayed for 4 days, $27 \%$ for 2 days, $22.4 \%$ for 34 days, and $8.6 \%$ for 5 days.

With reference to reason for visit, the majority of respondents $(52.6 \%)$ interest was related to culture. $20.4 \%$ of respondents came for educational purpose, while $18.4 \%$ of respondents came for the reason of relaxation.

With regard to membership in a group, the majority of respondents $(44.1 \%)$ traveled with a partner or friends/ family members and in an organized group (44.1\%). The rest traveled alone or in other forms.

\subsection{Descriptive statistics on the indicators of destination attributes and satisfaction}

As described earlier, one of the objectives of the current study was to determine tourist satisfaction with destination attributes at tourist attraction sites in Amhara Region. In this part the result of descriptive statistics on the indicators of destination attributes will be presented. Indicators of satisfaction included, accommodation ( 8 items), hospitality (23 items), accessibility ( 9 items), attractiveness (18 items), communication (13 items), environmental ( 8 items), infrastructural ( 4 items), cost (12 items), and others (2 items). Respondents were requested to evaluate these attributes using a 5 -point Likert-type scale (where $1=$ strongly disagree, $2=$ disagree, $3=$ neutral, 4 = agree, $5=$ strongly agree). Means and standard deviations were computed on all destination attributes and satisfaction variables. The results are summarized in Table 3. 
Table 3: Descriptive statistics on the indicators of destination attributes and satisfaction $(\mathrm{N}=152)$

\begin{tabular}{lrccr}
\hline & Min & Max & M & SD \\
\hline Satisfaction & 63.00 & 24.00 & 102 & 17.12 \\
Accommodation & 21.00 & 40.00 & 31.12 & 5.40 \\
Accessibility & 25.00 & 45.00 & 34.35 & 6.17 \\
Attractiveness & 32.00 & 90.00 & 69.51 & 15.98 \\
Communication & 24.00 & 65.00 & 47.84 & 11.71 \\
Environmental & 11.00 & 40.00 & 25.53 & 7.19 \\
Infrastructural & 3.00 & 20.00 & 11.84 & 4.57 \\
Cost & 30.00 & 60.00 & 46.25 & 8.97 \\
Others & 3.00 & 10.00 & 5.44 & 1.46 \\
& & & & \\
\hline
\end{tabular}

Satisfaction was assessed against 23 items. Mean scores for satisfaction was $102(S D=17.12)$, ranging from a low of 63.00 to a high level of 124.00. The result indicates high satisfaction of the tourist at destination sites.

Accommodation was assessed against 8 items on a scale from one to five. Mean score for destination accommodation was $31.12(S D=5.40)$, ranging from 21 to 40.00 . The result indicates high satisfaction on accommodation of the tourist destination sites.

Destination accessibility was assessed against 9 items. Mean scores for accessibility was $34.35(S D=6.17)$, ranging from a low of 25 to a high level of 45 . The result indicates high satisfaction on accessibility of the tourist destination sites.

Destination attractiveness was assessed against 18 items. Mean scores for attractiveness was 69.51 (SD $=15.98$ ), ranging from a low of 32 to a high level of 90 . The result indicates high satisfaction on attractiveness of the tourist destination sites.

Mean scores for communication was $47.84(S D=11.71)$ on a scale of five with 13 items. Mean scores ranged from 24.00 to 65.00 . The result indicates high satisfaction on the quality of communication of the tourist destination sites.

Environmental attractiveness was assessed with 8 items. Mean scores for environmental attractiveness was $25.53(S D=7.19)$, ranging from a low of 11 to a high level of 40 . The result indicates high satisfaction on attractiveness of the tourist destination sites.

Infrastructural quality was assessed with4 items. Mean scores for infrastructural quality was 11.84 (SD $=4.57$ ), ranging from a low of 3 to a high level of 20 . The result indicates high satisfaction on infrastructural quality of the tourist destination sites.

Cost was assessed with 12 items. Mean scores for infrastructural quality was $46.25(S D=8.97)$, ranging from a low of 30 to a high level of 60 . The result indicates high satisfaction on infrastructural quality of the tourist destination sites.

From the above table it appears that the mean value for all destinations attributes were above average, indicating that respondents generally agreed that destination attributes in the study areas are at satisfactory levels. Customer satisfaction is one the most areas being researched in many tourism studies due to its importance in determining the success and the continued existence of the tourism business (Gursoy et al., 2007). Service quality is considered as a standard used to assess the effectiveness of a particular leisure service agency, including the tourism service sector (Godbey, 1997), and therefore the quality of service involved with tourism plays an important role in the process of delivery (Wyllie, 2000). There is evidence to indicate that tourist satisfaction is a strong indicator of their intention to visit and recommend relevant destinations to others (Kozak, 2001; Yau and Chan, 1990). Many reasons cause tourists to be satisfied with their trip or journey, including the quality of the services provided, such as infrastructure, security, cleanliness, natural situation, consumer protection and easily obtained (Handszuh, 1995).

\subsection{Predictors of Tourists' Satisfaction}

The second major objective of the present study was to determine the relationships between the destination attributes and overall tourist satisfaction. Multiple regression analysis was conducted, using overall tourist satisfaction as the dependent variables and the eight destination related factors (accommodation, accessibility, attractiveness, communication, environmental, infrastructural, cost, and others) as independent variables. The purpose of this part of the investigation was to examine the extent to which the eight destinations related factors are associated with tourists' levels of satisfaction. To predict the goodness of- fit of the regression model, the multiple correlation coefficients (R), coefficient of determination (R2), and F ratio were examined. Table 4 shows the results of the regression analysis. 
Table 4: Regression analyses of destination factors as predictors of tourist satisfaction $(\mathrm{N}=152)$

\begin{tabular}{lccccc}
\hline Variables & $\mathrm{B}$ & SEB & $\beta$ & $t$-value & $p$-value \\
\hline Accommodation & -.457 & .352 & -.144 & -1.29 & .197 \\
Accessibility & -.507 & .206 & -.183 & -2.45 & .015 \\
Attractiveness & .592 & .105 & .552 & 5.62 & .000 \\
Communication & .758 & .128 & .519 & 5.90 & .000 \\
Environmental & .260 & .169 & .109 & 1.53 & .127 \\
Infrastructural & -1.40 & .321 & -.375 & -4.37 & .000 \\
Cost & .933 & .108 & .489 & 8.66 & .000 \\
Others & -1.50 & .580 & -.129 & -2.59 & .011 \\
$\mathrm{~F}=(8143)=77.908, \mathrm{R}=.902$, & $\mathrm{R}$ Square $=.813$, Adjusted R Square $=.803$ \\
\end{tabular}

The results of the regression analysis indicated that there was a significant relationship between destination related factors and tourist satisfaction, $F=(8,143)=77.908, p<.001$. The regression model, presented in Table 4 explained 80.3 percent of the total variance observed on tourists' satisfaction scores. As shown in the Table, six variables contributed significantly to prediction of the variance in tourist satisfaction. Attractiveness $(\beta=.552, p$ $=.010)$, communication $(\beta=.519, p=.000)$, cost $(\beta=.489, p=.000)$, infrastructural $(\beta=-.375, p=.000)$, accessibility $(\beta=-.183, p=.015)$, and others $(\beta-.129, p=.011)$ are significant factors contributing to overall satisfaction of tourist. The regression results indicated that attractiveness, communication, and cost had positive relationship with tourist satisfaction while infrastructural, accessibility, and others had negative relationship with tourist satisfaction.

The present study finding is consistent with other studies that linked destination related factors with tourist satisfaction (Gounaris et al., 2003; Howaidee, 2012). More specifically, the importance of destination attractiveness, communication, and cost has been demonstrated in prior research showing that if the destination improves the quality of tourists' attractiveness, communication, cost and other supportive products and services, the tourists' perceptions and satisfactions will be improved and vice versa (Kozark, \& Rimmington, 2000). A study conducted by Jay and Hsin (2007) found that the image of the hotel affected by the existence of service and customer satisfaction that support for the favorite image created by the hotel through the improvement of service quality and customer satisfaction.

Results highlight that the quality of the attractions has a positive influence on tourists' perception, which would lead them towards higher satisfaction levels. Attractions are the major determinants for tourists in selecting a destination, which are also known as the pull travel motives of the tourists. The results from this study are in keeping with other studies that reported attractions are the major determinants for tourists in selecting a destination, which are also known as the pull travel motives of the tourists.

In addition, these findings highlight the importance of the perception of fair price by tourists as it is considered in previous studies one consistent satisfaction attribute (Yu \& Goulden, 2006). Reasonable pricing of goods and services could improve the image of destination.

However, the results of the regression analysis indicated that there was negative relationship between destination infrastructural, accessibility and tourist satisfaction. Previous studies indicated that infrastructural and accessibility services and facilities are important predictors of tourist satisfaction (Yuksel, 2001). The availability and perceived quality of local transport at tourist destinations has been established as exercising an influence on visitor experience, overall satisfaction and repeat visitation (Thompson \& Schofield, 2007). In the Jordanian tourism industry, a study conducted by Abu Ali and Howaidee (2012) supported that destination facilities and accessibility and attraction directly influenced tourist satisfaction. Halpern (2008) suggest that improvements in transport infrastructure play a significant role in destination development and growth, particularly in peripheral destinations. Prideaux (2000) also highlights the importance of accessibility issues with destination development.

The lack of significant associations between accommodation and environmental and overall tourist satisfaction is also somewhat unexpected because the literature indicates that accommodation service quality especially at hotels is important as tourist accommodation is a central contributor to visitor satisfaction at host regions (Singh, 2006). Presbury, Fitzgerald and Chapman (2005) argue that accommodation is more than any other component of the tourist experience, and can have impacts on the course and outcome of the development of a tourist destination. In addition, Chan (2010) contends that the environment is the main attraction in customer experiences in ecologies. The more environmentally attractive destinations are, the more likely are they to be impacted on negatively by tourist traffic. 


\section{Conclusions}

This study investigated the effects of some destination attributes on the generation of customer satisfaction. This paper has yielded several findings of interest to the tourism industry quality debates and literature. The study's results are considered to be valuable to destination management, tourism organizations and business in Amhara Region in evaluating the level of their current services.

A total number of tourists participated in this study was 152 . Most tourists $(65.1 \%)$ were females. The majority of tourists $(28.9 \%)$ age was between 50 to 59 years; were married $(54.6 \%)$; hold $2^{\text {nd }}$ degree $(44.7 \%)$. American tourists $(30 \%)$ were the most people visiting tourist destination in Amhara Region, followed by European tourists (26.1\%), while African people (4.4\%) were the less.

The majority of tourists $(80.3 \%)$ arrived by air; Hear about tourist attraction sites from friends $(42.13 \%)$; were first time visitors(75.7\%); stayed for 4 days $(31.6 \%)$; came for culture interest $(52.6 \%)$, and traveled with a partner or friends, and family members $(44.1 \%)$.

Descriptive analyses revealed that the respondents rated most of the tourist destination attributes highly. The mean score for all destination attributes were above average means value, indicating that respondents generally agreed that destination attributes in the study areas are at satisfactory levels. This satisfaction can influence some behaviors such as to expand the length of stay and visit it again, customer retention as well as word-of-mouth or word-of-mouse processes.

The regression results indicated that destination attractiveness, communication, and cost had a positive relationship with tourist satisfaction while infrastructural, accessibility, and others had a negative relationship with tourist satisfaction. The study findings concluded that service quality (destination attractions, communication facilities) and cost has great effect on overall tourist satisfaction while destination accessibility and infrastructural have negative effect on overall tourist satisfaction. In conclusion, this study provides information that can be useful in the tourism industry to improve service quality. Satisfied tourists tend to communicate their positive experience to others (word of mouth) and they tend to buy the product repeatedly (rebuy)

Based on the results of this, the research makes recommendations for the various parties involved for increasing the satisfaction of foreign tourists.

Understanding tourist satisfaction is of utmost importance for the tourism industry, especially because of its effect on their future economy. The destination managers and marketers should maintain their efforts toward the tourist satisfaction endeavor. If the destination improves the quality of tourists' attractiveness, communication, cost and other supportive products and services, the tourists' perceptions and satisfactions of the tourists will be improved and vice versa. Thus, area of satisfaction to be considered by planners and marketers are maintaining attractiveness, communication, and cost.

Based on this study, areas that need to be greatly improved are destination accessibility and infrastructural attributes. The dissatisfaction of destination accessibility and infrastructural attributes is a matter of grave importance. Therefore, policy makers and managers in the tourism industry should consider infrastructural, accessibility, and others which can have a negative relationship with tourist satisfaction. It is necessary to improve accessibility and infrastructures and other facilities within and outside of the tourist destinations. It is recommended that tourists' satisfaction with accommodation is crucial. Furthermore, there should be viable programs to preserve and maintain the quality of attractions, customer education and interpretation programs for tourists' sites and community awareness programs to communicate the importance and benefits of tourism and to take preventive measures to overcome the negative impacts, etc

\section{References}

Abu Ali, J. \& Howaidee, M. (2012). The impact of service quality on tourist satisfaction in Jerash. Interdisciplinary Journal of Contemporary Research in Business. 3(12), 164-187.

Chan, A. (2004). Towards an improved understanding of tour services and customer satisfaction in package tours. Paper Presented at the Second Asia-Pacific CHRIE (APacCHRIE) Conference and Sixth Biennial Conference on Tourism in Asia, Phuket, Thailand.

Godbey, G. (1997). Leisure and leisure services in the 21st century. State College, PA: Venture Publishing.

Gounaris, S. P., Stathakopoulos, V. \& Athanassopoulos, A. D. (2003). Antecedents to perceived service quality: An exploratory study in the banking industry. The International Journal of Bank Marketing. 21(4/5), 168190.

Gursoy, D., McCleary, K. W. \& Lepsito, L. R. (2007). Propensity to complain: effects of personality and behavioral factors. Journal of Hospitality \& Tourism Research, 31 (3), 358-386.

Halpern, N. (2008). Lapland's Airports: Facilitating the development of international tourism in a peripheral region. Scandinavian Journal of Hospitality and Tourism, 8(1), 25 - 47.

Heung, V. C. S., Wong, M. Y., \& Qu, H. (2002). A study of tourists' satisfaction and post experience behavioral intentions in relation to airport restaurant services in the Hong Kong SAR. Journal of Travel \& Tourism 
Marketing, 12, 111-133.

Huh, J. (2002). Tourist satisfaction with cultural/heritage sites: The Virginia Historic Triangle. Master Thesis. Faculty of Virginia Polytechnic. Institute and State University. US.

Jay, K. \& Hsin, H. H. (2007). Do hoteliers need to manage image to retain loyal customers? International Journal of contemporary Hospitality Management, 19(6), 435-443.

Kozark, M. \& Rimmington, M. (2000). Tourist satisfaction with Mallorca, Spain, as an off- season holiday destination. Journal of Travel Research, 38, 260-269.

Presbury, R., Fitzgerald, A. \& Chapman, R. (2005). Impediments to improvements in service quality in luxury hotels. Managing Service Quality. 15(4), 357-373.

Prideaux, B. (2000). The role of the transport system in destination development. Tourism Management, 21(1), 53-63.

Singh, P. K. (2006). Hotel lodging and resort management: A service quality perspective. Kanishka Publishers: New Delhi.

Thompson, K. \& Schofield, P. (2007). An investigation of the relationship between public transport performance and destination satisfaction. Journal of Transport Geography, v. 15, 136-144.

Yu, L. L. \& Goulden, M. (2006). A comparative analysis of international tourists' satisfaction in Mongolia. Tourism Management, vol. 27, 1331-1342.

Yukesel A. (2000). Managing customer satisfaction and retention: A case of tourist destinations. Turkey Journal of Vacation Marketing, Vol. 7, 2, 153-168. 